\title{
S-Nitrosothiols signal hypoxia-mimetic vascular pathology
}

\author{
Lisa A. Palmer, ${ }^{1}$ Allan Doctor, ${ }^{1}$ Preeti Chhabra, ${ }^{1}$ Mary Lynn Sheram, ${ }^{1}$ Victor E. Laubach, ${ }^{2}$ \\ Molly Z. Karlinsey, ${ }^{3}$ Michael S. Forbes, ${ }^{1}$ Timothy Macdonald, ${ }^{3}$ and Benjamin Gaston ${ }^{1}$
}

${ }^{1}$ Department of Pediatrics and 2Department of Surgery, University of Virginia School of Medicine, and ${ }^{3}$ Department of Chemistry, University of Virginia, Charlottesville, Virginia, USA.

\begin{abstract}
NO transfer reactions between protein and peptide cysteines have been proposed to represent regulated signaling processes. We used the pharmaceutical antioxidant $N$-acetylcysteine (NAC) as a bait reactant to measure NO transfer reactions in blood and to study the vascular effects of these reactions in vivo. NAC was converted to $S$-nitroso- $N$-acetylcysteine (SNOAC), decreasing erythrocytic $S$-nitrosothiol content, both during wholeblood deoxygenation ex vivo and during a 3-week protocol in which mice received high-dose NAC in vivo. Strikingly, the NAC-treated mice developed pulmonary arterial hypertension (PAH) that mimicked the effects of chronic hypoxia. Moreover, systemic SNOAC administration recapitulated effects of both NAC and hypoxia. eNOS-deficient mice were protected from the effects of NAC but not SNOAC, suggesting that conversion of NAC to SNOAC was necessary for the development of PAH. These data reveal an unanticipated adverse effect of chronic NAC administration and introduce a new animal model of PAH. Moreover, evidence that conversion of NAC to SNOAC during blood deoxygenation is necessary for the development of PAH in this model challenges conventional views of oxygen sensing and of NO signaling.
\end{abstract}

\section{Introduction}

NO transfer reactions between protein and peptide cysteines have been proposed to represent regulated signaling processes $(1,2)$. For example, NO transfer from deoxygenated erythrocytes to glutathione ex vivo forms $S$-nitrosoglutathione (GSNO) (3). GSNO can signal acute vascular and central ventilatory effects characteristic of oxyhemoglobin desaturation (3-4) that are regulated by $\gamma$-glutamyl transpeptidase (GGT), GSNO reductase (GSNOR), and other enzymes (1,3-6). However, direct measurement of $S$-nitrosothiol signaling in vivo has proven challenging because of the metabolism and tissue-specific localization of endogenous $S$-nitrosothiol species $(1,3,4,6)$. We have addressed these challenges by using $N$-acetylcysteine (NAC) as a bait reactant, allowing the stable NO transfer product, $S$-nitroso- $N$-acetylcysteine (SNOAC), to be distinguished by mass spectrometry (MS) from endogenous $S$-nitrosothiols. We report that NAC is converted to SNOAC in mice in vivo. Furthermore, chronic, systemic administration of either NAC or SNOAC to mice causes hypoxia-mimetic pulmonary arterial hypertension (PAH). These data reveal a previously unappreciated vascular toxicity of NAC and of S-nitrosothiols. Moreover, they suggest that $S$-nitrosothiol transfer reactions can signal hypoxia in vivo.

$\mathrm{PAH}$ is characterized by increased pressure in the pulmonary arteries (PAs), increased RV weight, and thickening and remodeling of small PAs. Untreated human PAH can progress to right

Nonstandard abbreviations used: AE1, anion exchange protein 1; BPAEC, bovine pulmonary arterial cell; GGT, $\gamma$-glutamyl transpeptidase; Glut-1, glucose transport protein-1; GSNO, S-nitrosoglutathione; Hb, hemoglobin; HIF, hypoxia-inducible factor; HIMF, hypoxia-inducible mitogenic factor; MS, mass spectrometry; NAC, $\mathrm{N}$-acetylcysteine; $\mathrm{PA}$, pulmonary artery; $\mathrm{PAH}$, pulmonary arterial hypertension; $\mathrm{pO}_{2}$, partial pressure of $\mathrm{O}_{2}$; $\mathrm{PVHL}$, von Hippel-Lindau protein; SNOAC, S-nitroso- $N$-acetylcysteine; $\mathrm{SNO}_{\mathrm{rbc}}$, ratio of total erythrocytic $\mathrm{S}$-nitrosothiol concentration to $\mathrm{Hb}$; $\mathrm{Sp}$, specificity protein.

Conflict of interest: B. Gaston is a consultant for, and has licensed intellectual property to, Galleon Pharmaceuticals Inc. and N30 Pharmaceuticals LLC.

Citation for this article: J. Clin. Invest. 117:2592-2601 (2007). doi:10.1172/JCI29444. heart failure and death $(7,8)$. Chronic hypoxia can cause PAH, and hypoxia-regulated genes in the pulmonary endothelium play a role $(7,9)$. The partial pressure of $\mathrm{O}_{2}\left(\mathrm{pO}_{2}\right)$ of blood in the hypoxic PA is not as low as that used to study the expression of hypoxiamodified genes in vitro (10). However, endothelium-derived NO in erythrocytes can be transferred as a nitrosonium $\left(\mathrm{NO}^{+}\right)$equivalent to cysteine thiolates on glutathione (GSH) and anion exchange protein 1 (AE1) - forming GSNO and S-nitroso-AE1 - during erythrocytic oxyhemoglobin desaturation in vitro; this effect is dependent on erythrocytic oxyhemoglobin saturation rather than $\mathrm{pO}_{2}(3,4,11,12)$. S-Nitrosothiols, in turn, can increase the expression of hypoxia-associated gene regulatory proteins in vitro $(5,13$, $14)$, an effect regulated by $S$-nitrosothiol metabolic enzymes (5, 14). Here, we report a hypoxia-mimetic effect, pulmonary vascular remodeling, that is associated with chronic systemic conversion of NAC to SNOAC in vivo. Strikingly, chronic exogenous administration of SNOAC - a vasodilator (15) - recapitulates the effects of hypoxia on the lung, causing hypoxia-mimetic murine PAH. Furthermore, experiments in eNOS-deficient mice reveal that eNOS is necessary for NAC, but not SNOAC, to cause PAH. Taken together, these data demonstrate an unanticipated potential toxicity of chronic, systemic NAC and SNOAC administration and suggest a novel paradigm for understanding hypoxia-associated disease.

\section{Results}

NAC and SNOAC cause hypoxia-mimetic PAH. Three weeks of normobaric hypoxia (10\%) increased RV systolic pressure, RV weight (relative to $\mathrm{LV}$ and septum $[\mathrm{LV}+\mathrm{S}])$ and muscularization of small $(<80-\mu \mathrm{m})$ pulmonary arterioles in both C57BL/ 6 and C57BL/6/129SvEv mice ( $n=4-14$ each; Figure 1, A-E). The effects of 3 weeks' exposure to either NAC $(10 \mathrm{mg} / \mathrm{ml}[52 \mathrm{mM}])$ or SNOAC $(1 \mathrm{mM})$ in the drinking water were similar to those of 3 weeks' exposure to hypoxia in C57BL/6/129SvEv mice, increasing RV pressure $(n=3-4$ each, $P<0.001$ relative to normoxia), $\mathrm{RV} / \mathrm{LV}+\mathrm{S}$ weight ratio $(n=6-35$ each; $P<0.02$ relative to normoxia), and muscularization of the small pul- 

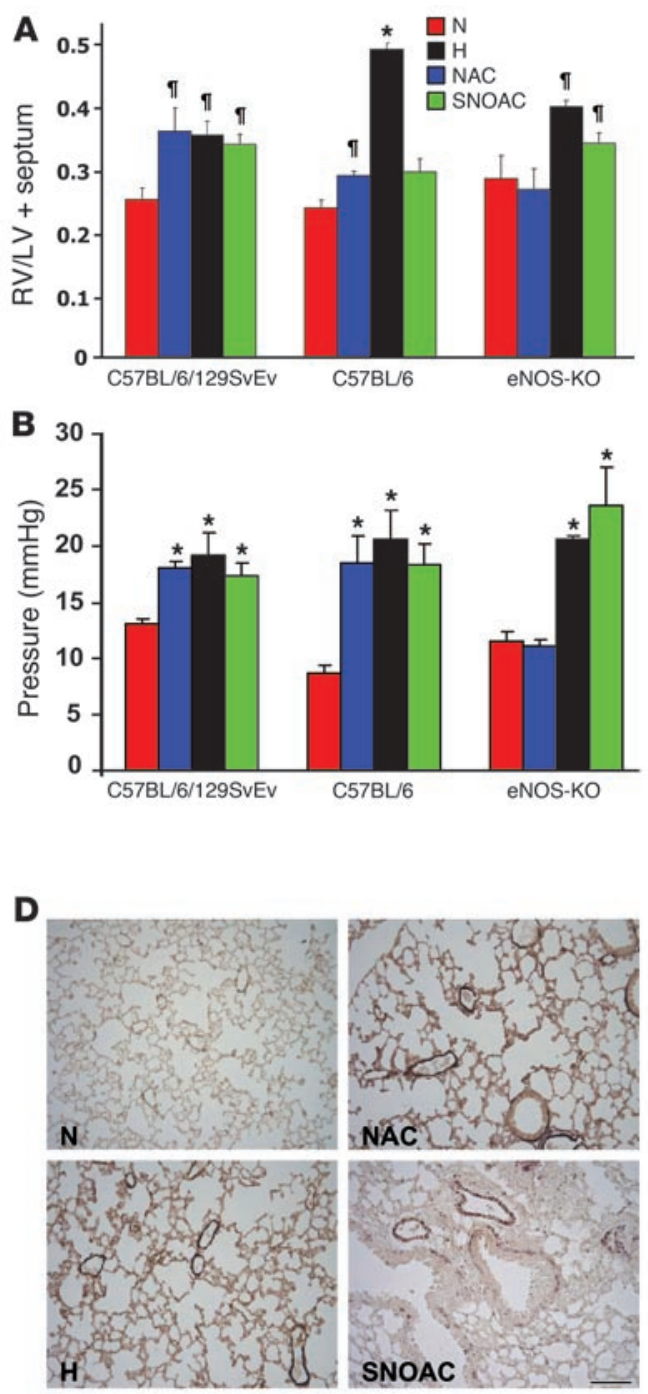
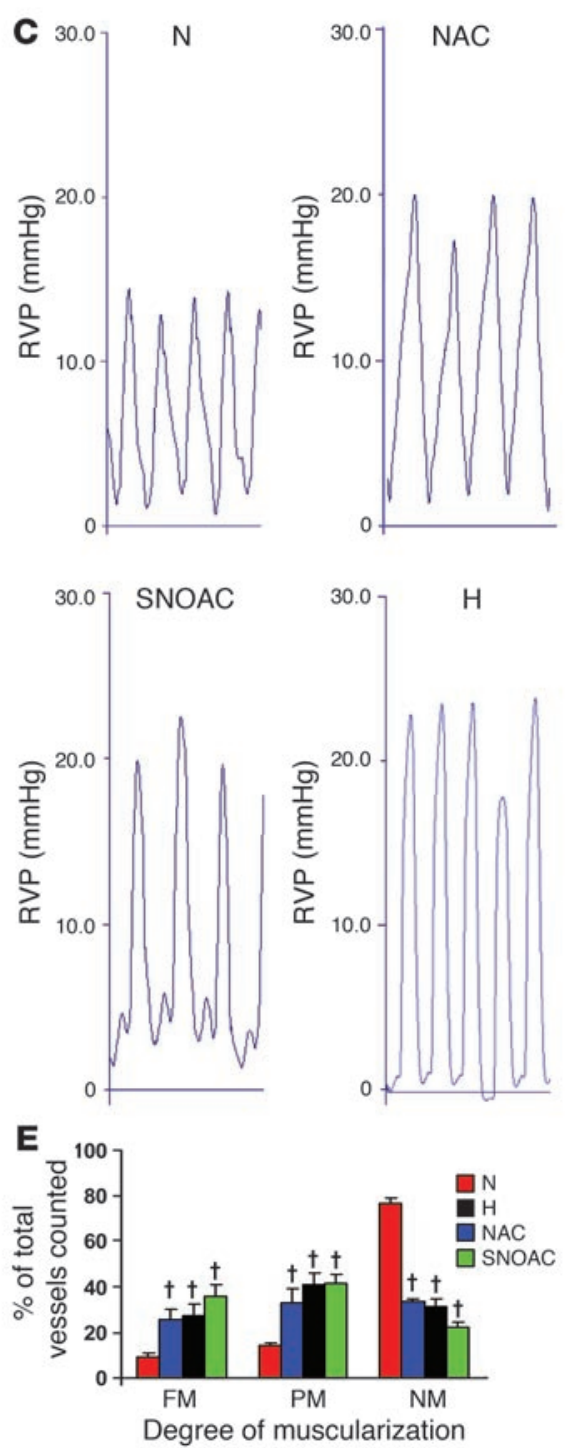

\section{Figure 1}

Systemic NAC and SNOAC cause hypoxia-mimetic $\mathrm{PAH}$ in mice. C57BL/6/ 129SvEv, C57BL/6, and eNOS-1male mice were maintained in normoxia $\left(\mathrm{N}\right.$, red; $\left.21 \% \mathrm{O}_{2}\right)$ or hypoxia $(\mathrm{H}$, black; $10 \% \mathrm{O}_{2}$ ); or were treated with NAC (blue) or SNOAC (green) in their drinking water for 3 weeks. (A) Relative $\mathrm{RV}$ weight was determined as the ratio of the weight of the RV to the LV+S weight. (B) RV systolic pressures were measured in the closed chest using a Millar 1.4 F catheter/transducer. (C) Representative RV pressure (RVP) tracings (each $=1 \mathrm{~s}$ ). (D) Lung section images from C57BL/6/129SvEv mice immunostained for von Willebrand factor and $\alpha$-SMA to illustrate changes in muscularization after 3 weeks of exposure to normoxia, hypoxia, NAC, or SNOAC. Scale bar: $100 \mu \mathrm{m}$ (applies to all panels). (E) Changes in muscularization in C57BL/6/129SvEv mice in the small $(<80-\mu \mathrm{m})$ vessels from histological sections (as in $\mathbf{D}$ ) counted by an observer blinded to the protocol. FM, fully muscular; PM, partly muscular, NM, nonmuscular. Significant increases in muscularization in each treatment group were seen in comparison to normoxic controls. Data are mean \pm SEM. $\rrbracket P<0.02,{ }^{*} P<0.001$, t $P<0.003$, by 1 -way ANOVA followed by pairwise comparison, all compared with normoxic control. monary arterioles. $(n=3-8 ; P<0.003$ relative to normoxia) (Figure $1, \mathrm{~A}-\mathrm{E})$. Of note, PA pressures in the treatment groups were greater than $125 \%$ those in controls in the hypoxia, NAC, and SNOAC groups, despite anesthesia, which can blunt PAH (ref. 8; Figure 1C). Similar results were obtained in C57BL/ 6 mice ( $n=4-12$ each); however, the increase in $\mathrm{RV} / \mathrm{LV}+\mathrm{S}$ ratio was not significant in these mice in the case of SNOAC (Figure 1, A and B).

In dose-response experiments, higher-dose NAC $(10 \mathrm{mg} / \mathrm{ml})$ increased RV weight relative to normoxia at 3 weeks in C57BL/6/ 129SvEv mice (Figure 1A); however, at a lower dose (1 mg/ml), RV/ $\mathrm{LV}+\mathrm{S}$ was normal at 3 weeks $(0.27 \pm 0.005 ; n=5 ; P=\mathrm{NS}$ compared with no treatment). On the other hand, low-dose NAC increased $\mathrm{RV}$ systolic pressure at 3 weeks to $27.5 \mathrm{mmHg}(n=4 ; P<0.04$ compared with normoxia).

In time course experiments performed using C57BL/6/ $129 \mathrm{SvEv}$ mice, there was a significant increase in RV pressure after 1 week of NAC exposure $(10 \mathrm{mg} / \mathrm{ml}$; mean RV pressure with NAC, $22.8 \pm 3.3 \mathrm{mmHg}$, versus without NAC, $13.7 \pm 0.7 \mathrm{mmHg}$; $n=5-8$ each; $P<0.01$ ), persisting at 2 and 3 weeks. $\mathrm{RV} / \mathrm{LV}+\mathrm{S}$ increased more slowly: a significant difference between NAC- exposed and -unexposed animals was not observed until 3 weeks $(n=5-8$ each at 1 and 2 weeks; $P=\mathrm{NS})$. Concomitant 3 -week exposure to both hypoxia and $10 \mathrm{mg} / \mathrm{ml} \mathrm{NAC}$ did not result in a greater increase in mean $\mathrm{RV} / \mathrm{LV}+\mathrm{S}(0.35 \pm 0.082$ after $\mathrm{NAC}$ and hypoxia together versus $0.34 \pm 0.020$ after hypoxia alone; $n=4-6$ each; $P=\mathrm{NS})$ or RV pressure $(21.4 \pm 1.30 \mathrm{mmHg}$ after NAC plus hypoxia versus $19.9 \pm 1.03 \mathrm{mmHg}$ after hypoxia alone; $n=4-6$ each; $P=\mathrm{NS}$ ), suggesting functional overlap between hypoxiaand NAC-stimulated pathways.

Whole-lung expression of hypoxia-inducible mitogenic factor (HIMF), fibronectin, and eNOS, proteins associated with the development of PAH in some models (16-20), was increased by hypoxia and by 3 weeks of NAC treatment $(10 \mathrm{mg} / \mathrm{ml} ; n=3-6$ each; $P<0.05$ [HIMF and fibronectin] and $P<0.01$ [eNOS]; Figure 2, A-D). Of note, VEGF-A and endothelin 1 protein expression did not increase significantly with hypoxia or NAC in our model (Figure 2, E and F). Though these proteins can be upregulated by low $\mathrm{pO}_{2}$ in vitro, results are variable in PAH models (21-26), suggesting that $\mathrm{PAH}$ associated vascular remodeling is more complex than would be predicted based on the effects of low $\mathrm{pO}_{2}$ alone. Indeed, VEGF and 

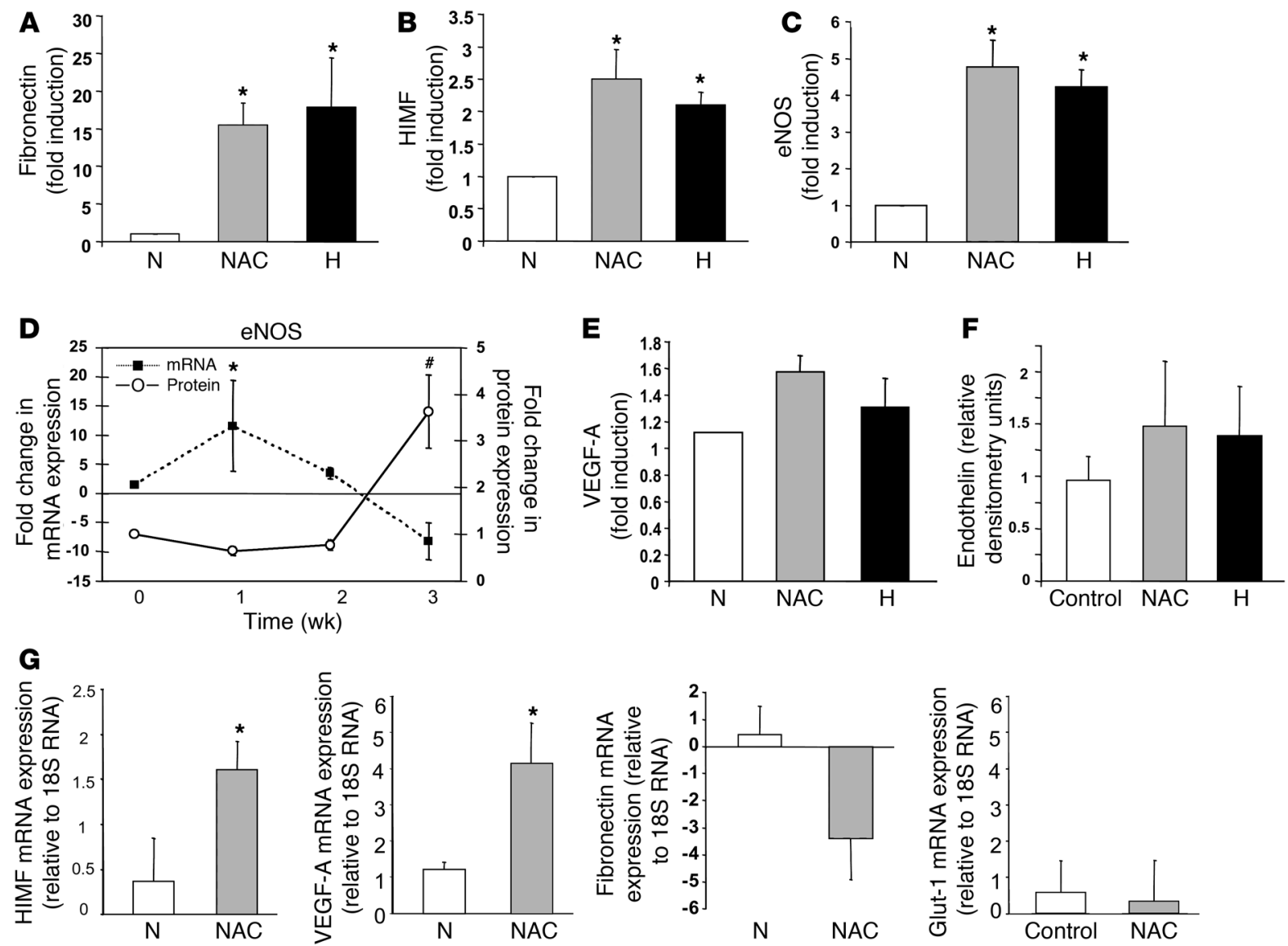

Figure 2

Three weeks of NAC treatment or hypoxia increases the whole-lung expression of certain genes associated with the development of PAH in mice. The expression of fibronectin (A), HIMF (B), eNOS (C and D), VEGF-A (E), and endothelin (F) in whole-lung homogenates from NACtreated mice was examined by immunoblot. Fold increase in density relative to MAPK (equal loading control) was determined for each condition. The increases in fibronectin, HIMF, and eNOS ( $n=3-5$ each) were significant. (G) Three weeks of NAC treatment also increased whole-lung mRNA, assayed relative to 18S RNA by RT-PCR, for HIMF and VEGF-A but not fibronectin or Glut-1 ( $n=3$ each). Time course analysis of NAC-treated mice (D) revealed that the increase in whole-lung eNOS mRNA (filled squares, left axis) preceded the increase in eNOS protein expression (open circles, right axis) but decreased by 3 weeks. ${ }^{*} P<0.05$; ${ }^{\#} P<0.01$.

eNOS expression can be associated with both protection against $\mathrm{PAH}$ and development of PAH, depending on the model and time course (18-29). NAC did not change expression of neuronal or inducible NOS isoforms at 3 weeks (data not shown). NAC exposure increased whole-lung HIMF mRNA expression and transiently increased eNOS mRNA (Figure 2, D and G). Interestingly, parallel increases in lung protein and mRNA were not observed for the expression of some genes known to be upregulated in hypoxia in vitro, either because of nonvascular expression measured in wholelung homogenates and/or because of the complexity of pathways involved in the response to hypoxia and the development of PAH in vivo. For example, mRNA levels for $V E G F-A$ increased after 3 weeks of NAC treatment $(n=3 ; P<0.04$; Figure $2 \mathrm{G})$, though there was no significant change in VEGF-A protein levels (Figure $2 \mathrm{E}$ ). On the other hand, the change in mRNA expression for fibronectin was not significant ( $n=2-5$ each; $P=N S$; Figure $2 \mathrm{G}$ ), though expression of the corresponding protein increased (described above; Figure 2A). Further, mRNA for glucose transport protein-1 (Glut-1), conventionally upregulated by hypoxia, did not increase $(n=3$; $P=\mathrm{NS}$ ). Consistent with this complexity, our time course analysis revealed an NAC-induced increase in whole-lung eNOS mRNA that preceded the NAC-induced increase in eNOS protein expression but was transient (Figure 2D).

Three weeks of NAC $(10 \mathrm{mg} / \mathrm{ml})$ did not affect systemic or portal vascular morphology (Supplemental Data; supplemental material available online with this article; doi:10.1172/ JCI29444DS1) or hemoglobin (Hb) $(12.5 \pm 0.64 \mathrm{~g} / \mathrm{dl}$ after NAC treatment versus $12.1 \pm 0.65 \mathrm{~g} / \mathrm{dl}$ in controls). Likewise, 3 weeks of oral SNOAC (1 mM) did not affect the systemic or portal vasculature (Supplemental Data).

NAC is converted to SNOAC in vivo and during erythrocytic deoxygenation in vitro and in vivo. The chemical mechanisms, including both inhibition of nitrosative/oxidative stress (30-32) and NO transfer chemistry $(1,33)$, by which NAC could cause PAH were investigated. NAC did not affect pulmonary vascular immunostaining for 3-nitrotyrosine (Supplemental Data), suggesting that its ability to cause PAH was not simply the result of tissue injury associated with altered nitrosative or oxidative stress.

In contrast, the ratio of total erythrocytic $S$-nitrosothiol concentration to $\mathrm{Hb}\left(\mathrm{SNO}_{\mathrm{rbc}}\right)(11)$ in NAC-treated mice $\left(1.0 \times 10^{-4} \pm\right.$ 

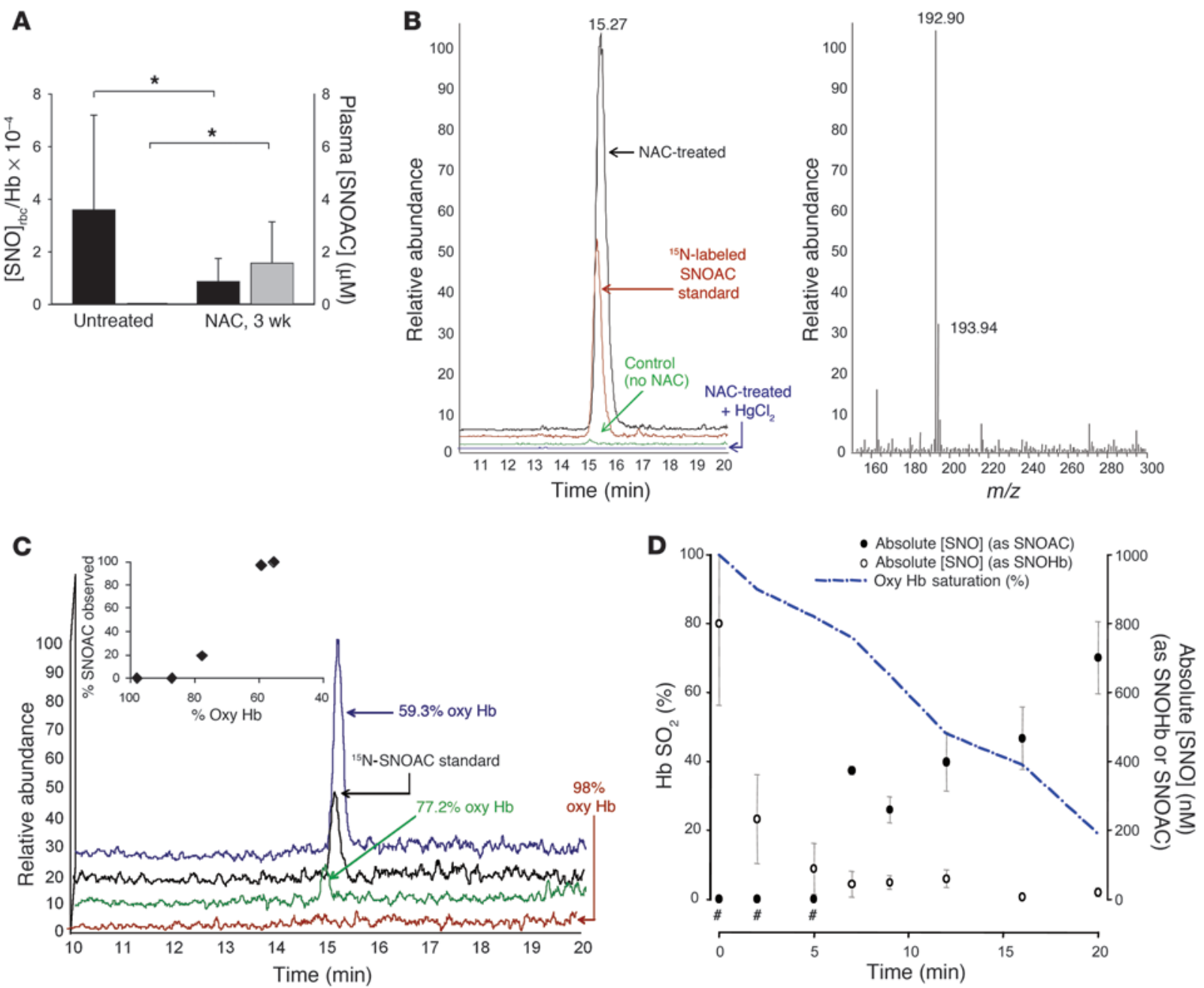

Figure 3

SNOAC is formed from NAC in blood ex vivo and in vivo. (A) The SNO $\mathrm{rbc}_{\text {in }}$ heparinized LV blood (black bars), measured by reductive chemiluminescence (11), was lower than normal following 3 weeks of treatment with $10 \mathrm{mg} / \mathrm{ml} \mathrm{NAC}(n=3-4$ each). In the same mice, plasma SNOAC levels (gray bars; measured by MS) increased from undetectable to approximately $2 \mu \mathrm{M}$ over the same time $\left({ }^{\star} P<0.05\right)$. (B) Serum SNOAC, measured by MS, formed in NAC-treated mice (3 weeks). Left: liquid chromatogram; right: MS spectrum. NAC-treated mice had a SNOAC peak ( $\mathrm{m} / \mathrm{z}$ 193; red) coeluting with ${ }^{15} \mathrm{~N}$-labeled SNOAC standard $(\mathrm{m} / \mathrm{z} 194$; black) that was absent in untreated animals (green) and was not detected in NAC-treated mice after serum pretreatment with $\mathrm{HgCl}_{2}$ to displace $\mathrm{NO}^{+}$from the thiolate (blue). (C) Oxygenated erythrocytes were deoxygenated ex vivo (argon; ref. 11) in the presence of $100 \mu \mathrm{M}$ NAC; supernatant SNOAC was measured by MS (above). SNOAC concentration increased with oxyhemoglobin $(\mathrm{Oxy} \mathrm{Hb})$ desaturation (co-oximetry: inset), being maximal at $59.3 \%$ saturation (blue), less at $77.2 \%$ saturation (green), and undetectable at $98 \%$ saturation. (D) SNOAC (filled circles) accumulated as the concentration of S-nitrosothiol-modified $\mathrm{Hb}$ (SNOHb; open circles) and oxyhemoglobin saturation $\left(\mathrm{Hb} \mathrm{SO}_{2}\right.$; blue line) both decreased in heparinized whole blood using argon with $5 \% \mathrm{CO}_{2}(\mathrm{pH} 7.3)$ in a tonometer. Both the increase in SNOAC and the loss of $\mathrm{SNO}_{\mathrm{rbc}}$ between 0 and 20 minutes were significant $(P<0.01$ by ANOVA followed by pairwise comparison to the maximum value; $n=3)$. "SNOAC levels were below the limit of detection when the oxyhemoglobin saturation was greater than $80 \%$.

$\left.0.7 \times 10^{-4} ; n=4\right)$ was lower than that in control animals $\left(3.7 \times 10^{-4}\right.$ $\pm 3.2 \times 10^{-4} ; n=3 ; P<0.05$; Figure $\left.3 \mathrm{~A}\right)$. Decreased $\mathrm{SNO}_{\mathrm{rbc}}$ content in NAC-treated mice could be expected if the NO group on erythrocytic protein thiols were transferred $(1,33)$ to NAC according to the reaction: protein-S-NO $+\mathrm{NAC} \rightarrow$ protein-SH + SNOAC. Therefore, the formation of plasma SNOAC was assayed by MS. SNOAC was identified in the RV plasma of the NAC-exposed animals $(1.6 \pm 0.9 \mu \mathrm{M}$ versus $0 \mu \mathrm{M}$ in unexposed animals; $P=0.04$; Figure $3 \mathrm{~A}$ ), a finding confirmed both by coelution with ${ }^{15} \mathrm{~N}$-labeled SNOAC and by NO displacement from the $S$-nitrosothiol bond using $\mathrm{HgCl}_{2}$ (11) (Figure 3B). SNOAC was not detected in the LV of NAC-treated animals $(n=7)$. Moreover, ex vivo human blood deoxygenation in the presence of NAC in a tonometer (in nitrogen with $5 \% \mathrm{CO}_{2} ; \mathrm{pH}$ maintained at 7.3 ; ref. 11) resulted in both loss of $\mathrm{SNO}_{\mathrm{rbc}}$ content and a nearly stoichiometric formation of SNOAC $(n=3 ; P<0.05$ by ANOVA followed by pairwise comparison with the maximal value; Figure $3, \mathrm{C}$ and $\mathrm{D}$ ). The concentration of SNOAC increased as the fraction of oxygenated $\mathrm{Hb}$ decreased in intact erythrocytes ex vivo (Figure 3D). There was no transfer from erythrocytes to NAC when blood was maintained at $100 \%$ saturation for 15 minutes (total $\mathrm{SNO}_{\mathrm{rbc}}$ was $2.1 \times 10^{-4} \pm 0.7 \times 10^{-4}$ initially and $2.0 \times 10^{-4} \pm 0.6 \times 10^{-4}$ at 15 minutes; SNOAC 


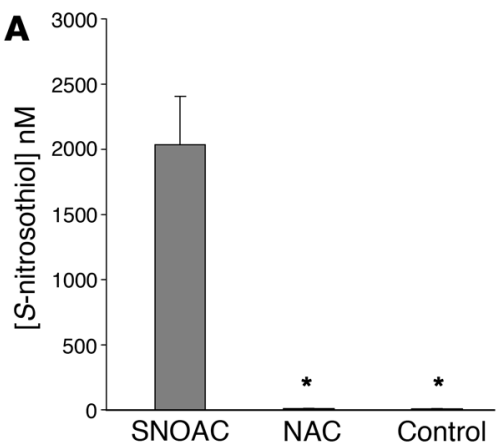

B
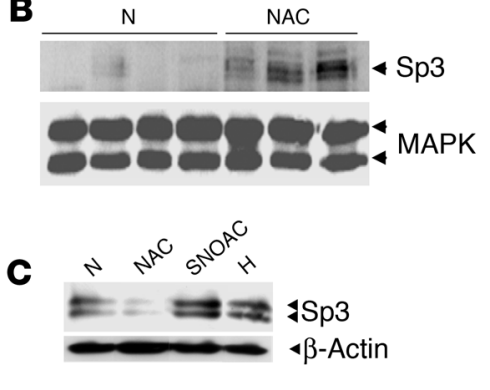

\section{Figure 4}

SNOAC recapitulates in primary pulmonary arterial endothelial cells the hypoxiamimetic whole-lung effect of chronic NAC administration on Sp3 expression in vivo. (A) One micromolar SNOAC, but not $50 \mu \mathrm{M} N A C$, treatment (4 hours each) increased intracellular $S$-nitrosothiol levels (assayed by $\mathrm{Cu}$ /cysteine chemiluminescence; ref. 11$)$ in primary murine pulmonary endothelial cells $\left({ }^{\star} P<0.05\right.$ compared with SNOAC treatment). (B) Immunoblot showing increased Sp3 expression relative to MAPK in the whole-lung homogenates of mice treated for 3 weeks with $10 \mathrm{mg} / \mathrm{ml} \mathrm{NAC}$ but not in those of control mice. By densitometry, this increase was significant $(P<0.01)$. (C) Paradoxically, however, NAC $(50 \mu \mathrm{M}$; 4 hours) did not increase Sp3 expression relative to $\beta$-actin in primary murine pulmonary endothelial cells in vitro, while both SNOAC ( $1 \mu \mathrm{M} ; 4$ hours) and hypoxia (10\%; 4 hours) did.

assayed by MS was undetectable). These findings are consistent with evidence that $\mathrm{SNO}_{\mathrm{rbc}}$ distribution is, in part, dependent on oxyhemoglobin saturation $(3,11,12)$ and that thiols accelerate the desaturation-induced loss of $\mathrm{SNO}_{\mathrm{rbc}}$ content (11). SNOAC formation was pseudo-first order (in excess NAC) and relatively slow $\left(\mathrm{k} \sim 5.3 \times 10^{-10} \mathrm{M} / \mathrm{s}\right)$.

We also considered that NAC could be converted to circulating SNOAC by reacting with NO in endothelial cells. S-Nitrosothiol concentrations in whole-cell lysates $(43 \pm 7.3 \mathrm{nM})$ were not increased by 4 hours' exposure to $50 \mu \mathrm{M}$ NAC in the presence of $5 \mu \mathrm{M}$ exogenous NO $(45 \pm 3.1 \mathrm{nM} ; P=\mathrm{NS} ; n=3)$. However, cellular levels were increased by exposure to $5 \mu \mathrm{M}$ SNOAC $(2.0 \pm 0.4 \mu \mathrm{M} ; n=3 ; P<0.05$ when compared with NAC alone and control; Figure 4A).

eNOS-deficient mice are protected from the bypoxia-mimetic effects of $N A C$. eNOS is proposed to be important for maintaining $\mathrm{SNO}_{\mathrm{rbc}}$ content (34). We studied NAC-induced PAH in $\mathrm{eNOS}^{-/-}$mice. The $\mathrm{SNO}_{\mathrm{rbc}}$ content of these mice was $0.39 \times 10^{-4} \pm 0.15 \times 10^{-4}$ (nearly a log order lower than in wild-type mice; $P=0.004$ ). At baseline, eNOS $^{-/}$mice had slight increases in RV pressure and RV weight relative to those of the wild-type background (C57BL/6) mice, as reported previously (refs. 27-29; Figure 1, A and B). Strikingly, eNOS-deficient mice were completely protected from NACinduced PAH - suggesting that the chronic effects of NAC to increase PAH are eNOS dependent - but they were not protected from SNOAC-induced PAH (Figure 1, A and B).

NAC could cause PAH in eNOS-replete mice by depleting endothelial $\mathrm{NO}$ or depleting eNOS-derived $\mathrm{SNO}_{\mathrm{rbc}}$ (ref. 34; Figure 3). However, (a) NAC was not converted to SNOAC in eNOSreplete pulmonary endothelial cells in culture, even in the presence of exogenous NO; (b) $\mathrm{SNO}_{\mathrm{rbc}}$ levels in $\mathrm{eNOS}^{-/-}$mice at baseline were lower than those in wild-type, NAC-treated mice; and (c) SNOAC caused, rather than ameliorating, $\mathrm{PAH}$ in $\mathrm{eNOS}^{-/-}$mice. Therefore, SNOAC excess, rather than endothelial $\mathrm{NO}$ or $\mathrm{SNO}_{\mathrm{rbc}}$ depletion, appears most likely to have caused PAH in our model.
Chronic GSNO exposure in normoxia does not cause PAH. GSNO is an endogenous $S$-nitrosothiol that is similar to SNOAC in the kinetics of its homolytic decomposition (35). Normoxic C57BL/6/129SvEv mice receiving $1 \mathrm{mM}$ GSNO in their drinking water for 3 weeks did not develop $\mathrm{PAH}$ as measured by any parameter $(n=3$ in the GSNO group and 20 in the untreated control group; $P=\mathrm{NS}$ ).

The molecular effects of S-nitrosothiols in vitro are bypoxia mimetic and recapitulate whole-lung effects of NAC in vivo. $S$-Nitrosothiols can have hypoxia-mimetic gene-regulatory effects involving the expression of transcription factors relevant to pulmonary vascular disease, including the hypoxia-inducible factor $(\operatorname{HIF})(5,13)$ and specificity protein (Sp) families (14). HIF 1, HIF 2, $\mathrm{Sp} 1$, and $\mathrm{Sp} 3$ are involved in regulating the expression of the genes upregulated in the lungs of mice treated chronically with $\operatorname{NAC}(9,16,17,24,25,36)$. Because the expression and activity of the HIF and $\mathrm{Sp}$ families are affected by $S$-nitrosothiols in vitro $(5,13,14,37$, 38 ), we tested whether chronic NAC or SNOAC could affect their pulmonary expression in mice. Interestingly, NAC increased whole-lung Sp3 expression in vivo but not in primary pulmonary vascular endothelial cells in vitro (Figure 4, B and C). SNOAC, on the other hand, increased both intracellular S-nitrosothiol levels and nuclear Sp3 expression in primary murine pulmonary vascular endothelial cells (Figure 4, A and C). Thus, conversion of NAC to SNOAC (as shown in Figure 3) could be one explanation for the paradox that NAC can increase Sp3 expression in vivo but not in vitro.

Similarly, NAC increased HIF 1 activity in whole-lung extracts in vivo (Figure 5A), though NAC suppresses upregulation of HIF $1 \alpha$, the oxygen-labile subunit of HIF 1 , by both substance P (31) and by oxidized low-density lipoprotein (32) in vitro. As with Sp3, conversion of NAC to SNOAC may help to explain this paradox: SNOAC and hypoxia, but not NAC, increased HIF $1 \alpha$ expression, relative to $\beta$ actin, in primary pulmonary vascular endothelial cells in vitro (Figure $5 \mathrm{~B}$ ). This is consistent with previous work showing HIF $1 \alpha$ stabilization by GSNO $(5,13)$; indeed, we found that GSNO reduced HIF $1 \alpha$ monoubiquitination in bovine pulmonary arterial cells (BPAECs) expressing HA-tagged HIF $1 \alpha$ and a histidine-tagged, dominant-negative ubiquitin that stops ubiquitin chain propagation (K48R DN-Ub) (Figure 5C).

Mechanisms by which $S$-nitrosothiols inhibit HIF $1 \alpha$ ubiquitination and degradation are complex, involving both NO-radical reactions and transnitrosation reactions $(1,5,13,37-40)$. Low-micromolar SNOAC levels derived from NAC in vivo (Figure 3 ) would not generate concentrations of intravascular $\mathrm{NO}$ radical relevant to endothelial gene regulation (38) in the presence of millimolar concentrations of intravascular $\mathrm{Hb}$ (41); therefore, signaling through transnitrosation chemistry would seem more likely to be relevant to our in vivo model. NO transfer between thiols could stabilize HIF $1 \alpha$ through effects on prolyl hydroxylase, Akt signaling, and HIF $1 \alpha$ itself $(13,37-43)$. In addition, GSNO modifies E3 ubiquitin ligases through transnitrosation (44). Both SNOAC (Figure 5D) and GSNO (data not shown) inhibit the coimmunoprecipitation of HIF $1 \alpha$ with its E3 ligase, von Hippel-Lindau protein (pVHL) (45) in COS cells overexpressing both FLAG-tagged PVHL and HAtagged HIF $1 \alpha$. Strikingly, SNOAC S-nitrosylated native pVHL in HeLa cells (Figure 5E), and SNOAC and GSNO increased PVHL 


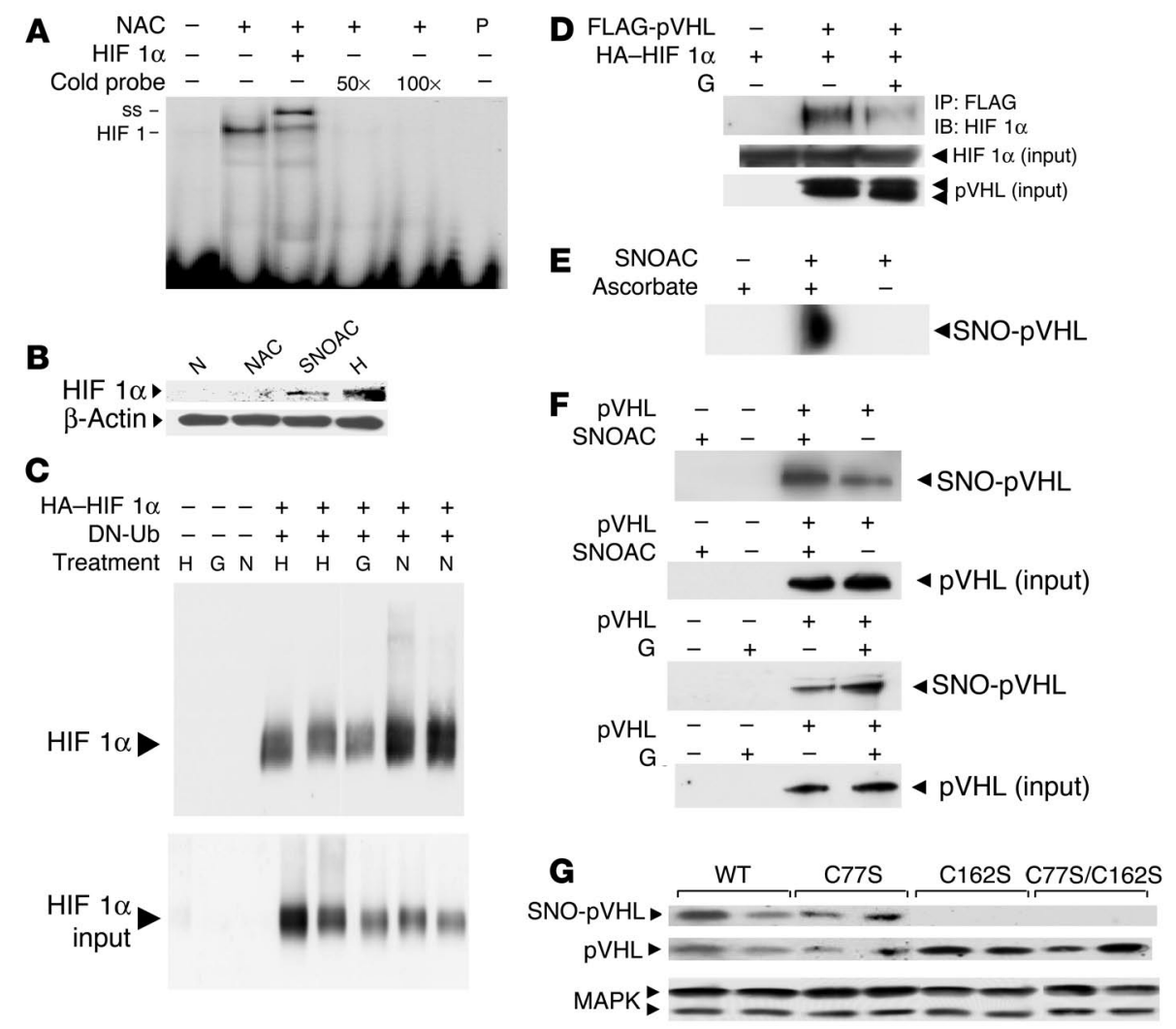

Figure 5

S-Nitrosothiols prevent normoxic ubiquitination and degradation of HIF 1 $\alpha$. (A) NAC treatment (10 $\mathrm{mg} / \mathrm{ml}$; 3 weeks) increased whole-lung HIF 1-DNA binding activity. Complexes were supershifted (ss) with anti-HIF $1 \beta$ and eliminated with excess cold probe (P). (B) SNOAC (1 $\mu \mathrm{M})$, like GSNO (5, 13,38 ), increased normoxic HIF $1 \alpha$ expression in nuclear extracts isolated from primary murine pulmonary endothelial cells. NAC alone $(50 \mu \mathrm{M})$ did not affect HIF $1 \alpha$ expression. $\beta$-Actin was used as a protein load control. (C) In BPAECs transfected with HA-tagged HIF $1 \alpha$ and dominant-negative His-6-Myc-tagged ubiquitin (DN-Ub), ubiquitinated proteins were isolated using a nickel column and immunoblotted for HIF $1 \alpha$. Both hypoxia and GSNO (G; $10 \mu \mathrm{M})$ inhibited HIF $1 \alpha$ ubiquitination relative to normoxia. (D) In COS cells cotransfected with HA-tagged HIF $1 \alpha$ and FLAG-tagged pVHL, GSNO $(10 \mu \mathrm{M})$ prevented the coimmunoprecipitation of HIF $1 \alpha$ with pVHL. (E) S-nitrosylation of pVHL by SNOAC $(5 \mu \mathrm{M})$ in equal protein aliquots isolated from HeLa cells was identified by biotin substitution (49); in the absence of ascorbate, S-nitrosylated pVHL was not detected. (F) Similarly, SNOAC and GSNO (5 $\mu \mathrm{M})$ increased pVHL S-nitrosylation in pVHL-overexpressing 786-O cells. (G) C162, but not C77, was identified by biotin substitution to be $S$-nitrosylated in BPAECs transfected with wild-type cysteine 77 to serine mutant (C77S), C162S, or combined C77S/C162S pVHL exposed to SNOAC $(1 \mu \mathrm{M})$. Native $\mathrm{pVHL}$ and MAPK immunoblots represented the $\mathrm{pVHL}$ expression and protein load controls, respectively. All in vitro treatments were for 4 hours.

S-nitrosylation in 786-O cells stably overexpressing pVHL (45), in which baseline NOS activity and/or NO transfer reactions (1) also resulted in baseline pVHL $S$-nitrosylation (Figure 5F). Therefore, we studied the 2 potential pVHL $S$-nitrosylation targets (C77 and C162; refs. 45, 46). In BPAECs transiently transfected with wildtype PVHL or with cysteine-to-serine mutants C77S, C162S, or C77S/C162S, mutation of C162 eliminated SNOAC-induced PVHL $S$-nitrosylation (Figure 5G), consistent with evidence that C162 is required for $\mathrm{PVHL}$ to bind elongin $\mathrm{C}$ and ubiquitinate $\mathrm{HIF} 1 \alpha(46)$. Note that this effect could also reflect $S$-nitrosylation of a protein interacting with pVHL C162. Taken together, these data suggest that one element of the mechanism by which $S$-nitrosothiols may be hypoxia-mimetic involves prevention of HIF $1 \alpha$ ubiquitination, possibly through S-nitrosylation of pVHL C162. Additional stud- ies are needed to determine the extent to which each mechanism is involved in the hypoxia-mimetic vascular effects of SNOAC in vivo.

\section{Discussion}

In vitro evidence has suggested that NO transfer reactions occurring during erythrocyte deoxygenation may signal hypoxia $(3-5,11,12)$. However, the relevance of these reactions to hypoxia-associated processes at the wholeorganism level has not previously been directly demonstrated. Here, we used the pharmaceutical antioxidant NAC as a bait reactant to study this biochemistry in vivo. We report that chronic NAC administration to normoxic mice can cause increased RV pressure, RV hypertrophy, and pulmonary vascular remodeling that are indistinguishable from the effects of chronic hypoxia.

NAC must be converted to SNOAC to cause $P A H$. Several observations suggest that the chronic pulmonary vascular effects of NAC require conversion of NAC to SNOAC. To begin with, chronic treatment with both NAC and SNOAC caused PAH (Figure 1). Thus, PAH must have resulted from 1 of 4 pathways: (a) NAC was converted to SNOAC to cause PAH; (b) SNOAC was converted to NAC to cause PAH; (c) both NAC and SNOAC caused PAH, each by a separate mechanism; or (d) the generation of a third metabolite from both NAC and SNOAC caused PAH.

Second, eNOS ${ }^{-/-}$mice had decreased circulating $\mathrm{SNO}_{\mathrm{rbc}}$ content and were protected from NAC-induced $\mathrm{PAH}$ but were not protected from SNOACinduced PAH. These data suggest that SNOAC formation from high concentrations of NAC and eNOS-derived NO, rather than reduction of lower concentrations of SNOAC to NAC, was necessary for the development of PAH. They suggest that neither NAC alone nor a common NAC/SNOAC metabolite causes PAH.

Third, we identified an oxyhemoglobin saturation-dependent mechanism by which NAC was converted to SNOAC under physiological conditions in blood. SNOAC concentrations, measured by $\mathrm{MS}$, increased with the loss of $\mathrm{SNO}_{\mathrm{rbc}}$ content during whole-blood deoxygenation in the presence of NAC ex vivo (Figure 3), consistent with previously reported NO transfer from deoxygenated erythrocytes to GSH to form GSNO (3). Neither SNOAC nor GSNO (3) were formed in the presence of oxygenated blood: deoxygenation was necessary. Alternative mechanisms by which NAC could be converted to SNOAC involve reactions in which $\mathrm{NO}$ radical either: (a) is oxidized in nonerythrocytic cells to an $\mathrm{NO}^{+}$equivalent $-\mathrm{a}$ slow reaction under physiological conditions - that, in turn, reacts 
with NAC thiolate; or (b) reacts directly with NAC as a thiyl radical. These mechanisms are not kinetically favored in the context of competing reactions with excess heme or in the setting of hypoxia $(1,11,40)$, and they were not observed experimentally in the current study: NAC had minimal reactivity with endogenous or exogenous endothelial NO. Taken together, these data suggest that erythrocyte deoxygenation resulted in conversion of NAC to SNOAC.

Fourth, NAC given systemically to the mice was converted to SNOAC in vivo, as identified by MS in RV (deoxygenated) blood. Levels of SNOAC were undetectable in LV (oxygenated) blood, suggesting that SNOAC was lost across the pulmonary vasculature and/or (consistent with our data) not formed from NAC in the presence of oxygenated erythrocytes. Further, chronic NAC administration depleted $\mathrm{SNO}_{\mathrm{rbc}}$ content in vivo (Figure 3). Thus, the transnitrosation of an $\mathrm{NO}^{+}$equivalent from erythrocyte to NAC can explain SNOAC formation from NAC in vivo, consistent with previous observations $(3,11)$.

Note that these data, coupled with evidence that low levels of $\mathrm{NO}$ radical react minimally with thiols in isolated endothelial cells and in oxygenated erythrocytes, argue against a model in which NAC causes PAH simply by depleting endothelial NO. They also argue against a model in which $\mathrm{SNO}_{\mathrm{rbc}}$ depletion causes NAC-associated PAH. Humans with hypoxia-associated PAH are deficient in $S$-nitrosothiol-modified $\mathrm{Hb}$ (34); the relevance of this deficiency to PAH in hypoxic humans is not contradicted by our data. Indeed, we show that $\mathrm{NOS}^{-/}$mice have a modest baseline increase in PA pressure associated with $\mathrm{SNO}_{\mathrm{rbc}}$ depletion. However, chronic SNOAC treatment itself caused PAH in excess of that caused by $\mathrm{SNO}_{\mathrm{rbc}}$ depletion.

Last, NAC-derived SNOAC is hypoxia-mimetic at the cellular level, whereas NAC itself opposes cellular effects associated with hypoxia $(31,32)$. SNOAC increases $S$-nitrosothiol levels in primary pulmonary vascular endothelial cells (Figure 4). S-nitrosothiols can upregulate hypoxia-associated genes in vitro through HIFs and/or Sp's $(5,13,14,38)$. In whole-lung homogenates, significant increases in mRNA and protein expression for genes associated with hypoxic pulmonary vascular remodeling were not uniform. This may reflect the use of whole-lung homogenates and the expression of genes in nonvascular cells. Nevertheless, mRNA and protein expression increased for several genes regulated by HIF $1, \mathrm{Sp} 3$, and other hypoxia-associated factors. In the NAC-treated animals, it is unlikely that these effects on gene expression represented an effect of NAC alone: NAC (a) prevents hypoxia-mimetic cell injury in the absence of erythrocytes in vitro $(31,32)$; (b) did not cause PAH in the $\mathrm{NOS}^{-/-}$mice (Figure 1); and (c) did not increase Sp3 or HIF $1 \alpha$ expression in vitro (Figures 4 and 5). Taken together, these data suggest that conversion of NAC to SNOAC was necessary for the hypoxia-mimetic effects of chronic, systemic NAC exposure.

Mechanisms by which S-nitrosothiols could be hypoxia mimetic at the cellular level. SNOAC could interact with cellular proteins to cause pulmonary vascular remodeling through: (a) homolytic cleavage to form NO radical, which reacts downstream with cellular free radicals or heme groups according to diffusion-limited kinetics; or (b) transnitrosation reactions, in which $\mathrm{NO}$ is transferred to a target cysteine thiol, conventionally represented as a covalent $\mathrm{NO}^{+}$ transfer between thiolate anions (1). The interactions of $S$-nitrosothiols with gene-regulatory proteins such as HIF $1 \alpha$ are complex and likely involve both NO radical chemistry and transnitrosation chemistry (38). In the context of hypoxia and/or oxidative stress in vitro, both NAC alone and $S$-nitrosothiol-derived NO radical can affect HIF 1 activation through mechanisms involving consumption of free radicals $(38,40)$. However, transnitrosation chemistry may be more relevant to our in vivo model because plasma $S$-nitrosothiols likely evolve little or no bioavailable NO radical in the presence of blood $(1,11,41)$.

There are several potential targets of transnitrosation chemistry by which $S$-nitrosothiols might affect hypoxia-associated gene regulation. HIF $1 \alpha$ and prolyl hydroxylases could be modified by transnitrosation chemistry (37-39); and there may be targets in the Akt signaling cascade (13). Our results demonstrate that pVHL is also a target for $S$-nitrosylation. This posttranslational modification of $\mathrm{PVHL}$ appears to alter $\mathrm{PVHL}-\mathrm{HIF} 1 \alpha$ interaction and decrease HIF $1 \alpha$ ubiquitination. Of pVHL's 2 critical reactive cysteines, our data suggest that $\mathrm{C} 162$, which is necessary for the interaction of PVHL with elongin $\mathrm{C}$ within the HIF-E3 ligase complex $(46,47)$, is the likely target for $S$-nitrosylation. Additional work will be required to determine which mechanisms are the most important determinants of the hypoxia-mimetic cellular effects of SNOAC in our in vivo model.

Specific pulmonary effect of SNOAC. Oral administration of GSNO, an endogenous $S$-nitrosothiol (35) formed during erythrocyte deoxygenation (3), did not cause PAH, though GSNO has hypoxiamimetic effects in vitro $(5,13,14)$. This suggests that GSNO toxicity is prevented by mechanisms that may be bypassed by SNOAC. GGT cleaves GSNO to $S$-nitrosocysteinyl glycine and glutamate, serving as a gatekeeper in certain cells to regulate intracellular GSNO effects (3). SNOAC can bypass this regulation. However, pulmonary vascular endothelial cells express functional GGT (5). Therefore, we propose that the pulmonary vasculature is protected from oral GSNO, in part, by gastrointestinal GSNO metabolism (6). Additionally, NAC and SNOAC did not affect the kidney or liver; systemic vascular beds may be insensitive to SNOAC.

Alternatively, slow transnitrosation kinetics (Figure 3) may cause SNOAC to be formed only gradually as hypoxic systemic blood returns to the right heart, favoring an effect of SNOAC on the pulmonary vascular bed, where it is consumed before returning to the systemic circulation. However, mice fed SNOAC for 3 weeks at a dose that caused PAH had no change in portal histology. Therefore, we speculate that the pulmonary vascular bed is selectively sensitive to SNOAC, perhaps reflecting differential pulmonary expression of $S$-nitrosothiol metabolic enzymes (6). In this regard, the pulmonary vascular bed is susceptible to remodeling in the face of increased flow, chronic inflammation, and chronic hypoxia (7); each of these conditions could lead to increased $S$-nitrosothiol delivery to the lung. A fuller understanding of regional $S$-nitrosothiol metabolism, perhaps in animals in which long-term intra-arterial $S$-nitrosothiols can be delivered, will likely prove to be important.

The role of eNOS in this model of $P A H$. eNOS has been reported to have opposing roles in PAH (18-21, 26-29). An increase in pulmonary eNOS expression, described in certain species early in the course of PAH, may have a compensatory pulmonary vasodilator role. Consistent with this paradigm, we observed a transient increase in eNOS mRNA as well as a later increase in eNOS protein in PAH. On the other hand, the upregulation of eNOS protein could also represent a feed-forward mechanism by which SNOAC worsens pulmonary vascular remodeling, since $\mathrm{eNOS}^{-/-}$mice were protected from NAC-induced $\mathrm{PAH}$.

The role of eNOS in chronic PAH certainly involves effects in addition to an eNOS-associated increase in $S$-nitrosothiol deliv- 
Table 1

Primers used for PCR experiments

\begin{tabular}{ll}
\hline Gene & \multicolumn{1}{c}{ Primers } \\
HIMF (51) & Forward: 5'-GGTCCCAGTGCATATGGATGAGACCATAGA-3' \\
& Reverse: 5'-CACCTCTTCACTCGAGGGACAGTTGGCAGC-3' \\
VEGF-A (52) & Forward: 5'-CTCTACCTCCACCATGCCAAG-3' \\
& Reverse: 5'-GGTACTCCTGGAGGATGTCCACC-3' \\
Glut-1 (53) & Forward: 5'-GGTGTGCAGCAGCCTGTGTA-3' \\
& Reverse: 5'-AAATGAGGTGCAGGGTCCGT-3' \\
eNOS & Forward: 5'-AAGACAAGGCAGCGGTGGAA-3' \\
& Reverse: 5'-GCAGGGGGACAGGAATAGTT-3'
\end{tabular}

ery to the pulmonary vascular bed: $\mathrm{NOS}^{-/-}$mice have increased PA pressure at baseline, suggesting a role of eNOS on pulmonary vascular smooth muscle tone. These potential opposing roles for eNOS in regulating pulmonary vascular gene expression and smooth muscle tone might help to explain paradoxical observations regarding pulmonary vascular eNOS expression and activity in the setting of PAH.

Conclusions. Chronic exposure to NAC and to SNOAC causes murine PAH. We propose that these observations may be understood according to the following pathway. In normoxic, NACtreated animals, oxyhemoglobin desaturation in erythrocytes leads to SNOAC formation in systemic blood returning to the lungs. These reactions require the presence of endogenous $\mathrm{SNO}_{\mathrm{rbc}}$ formed, in part, by eNOS. Formation of SNOAC - like that of GSNO, S-nitrosothiol-AE1, and other $S$-nitrosothiols during erythrocyte deoxygenation - is dependent on transnitrosation reactions. In these reactions, an $\mathrm{NO}^{+}$equivalent, protected from heme autocapture, is transferred from one thiolate moiety to another as $\mathrm{Hb}$ changes conformation during deoxygenation $(1,3,4,11,12)$. The demonstration that SNOAC is formed during blood deoxygenation in vitro is complemented by the direct demonstration that it is present in hypoxic, but not normoxic, blood in vivo. While the cellular effects of GSNO and other $S$-nitrosothiols are regulated $(1,3,5,6,14)$, delivery of NO to the pulmonary endothelium by SNOAC appears to bypass this regulation, causing hypoxia-mimetic effects. These observations may help to explain hypoxia-mimetic effects of systemic NAC therapy observed in humans in vivo (48).

The effect of chronic NAC exposure to cause pulmonary vascular pathology may be species dependent. It is reassuring that the NAC dose that caused PAH in mice was higher than the hypoxiamimetic dose used in humans (48). However, PAH can be subclinical, even presenting as a terminal event $(7,8)$. In this context, it is noteworthy that NAC treatment may fail to decrease mortality in human clinical trials, despite beneficial antiinflammatory and antioxidant effects (30): PAH has not previously been considered as a NAC toxicity. Surveillance for this toxicity may be appropriate for long-term human trials with NAC.

In summary, these data: (a) provide the first in vivo measurements to our knowledge suggesting that NO can signal erythrocytic oxygen desaturation through $S$-nitrosothiol formation; (b) introduce a novel murine model of PAH, one in which transgenic animals are informative; (c) provide one explanation for previously reported, hypoxia-mimetic effects of NAC; and (d) suggest that PAH may be an unappreciated risk of systemic therapy with the pharmaceutical antiinflammatory and antioxidant agent NAC.

\section{Methods}

Animal protocols. C57BL/6/129SvEv, C57BL/6, and $\mathrm{eNOS}^{-/-}$mice (10-12 weeks old) were treated in normoxia $\left(21 \% \mathrm{O}_{2}\right)$ or hypoxia $\left(10 \% \mathrm{O}_{2}\right.$, normobaric) as described (27) with or without $10 \mathrm{mg} / \mathrm{ml} \mathrm{NAC}$ in the drinking water for 3 weeks (achieving serum NAC levels of $16.2 \pm 4.3 \mu \mathrm{M}$ as measured by liquid chromatography/MS). The plasma NAC level at this dose was similar to the target peak level in the human study of the hypoxiamimetic effects of NAC (48), though the dose per weight was approximately 40 -fold higher and the exposure continuous. Additional mice were treated for 3 weeks with $1 \mathrm{mM} \mathrm{SNOAC}$ in the drinking water (achieving venous plasma SNOAC levels of $350 \pm 34 \mathrm{nM}$ ). The $\mathrm{eNOS}^{-1-}$ mice used in these studies were on a C57BL/ 6 background, maintained by our group and backcrossed for 10 generations (27). Protocols were approved by the University of Virginia Animal Care and Use Committee.

$R V$ pressure measurements. A Millar Mikro Tip catheter/transducer (1.4 F) was inserted through the external jugular vein of sedated $(5 \mathrm{mg} / \mathrm{ml}$ pentobarbital) mice and threaded into the RV. RV pressure was determined from the average of 10-12 measurements (PulmoDyne; Hugo Sachs Elektronik) at a stable baseline (Figure 1C).

Immunohistochemistry, vessel morphometry, and ventricular weight ratio measurements. Inflated lungs fixed in $10 \%$ formaldehyde were assessed for endothelium and smooth muscle using antibodies for von Willebrand factor and $\alpha$-SMA (A0082 and M0851; Dako). Vessel morphometry was performed ( $>50$ vessels per animal) by an investigator blinded to the treatment group. Muscularization of small $(<80-\mu \mathrm{m})$ vessels was classified as nonmuscular, partly muscular, or muscular based on $\alpha$-SMA staining. Immunostaining for 3-nitrotyrosine was performed using anti-nitrotyrosine antibody (Upstate; Supplemental Data). Cardiac tissue was dissected free from the great vessels immediately post mortem and washed with PBS. RV tissue was dissected from the septum and LV; RV weight was expressed as the ratio $\mathrm{RV} / \mathrm{LV}+\mathrm{S}$.

NO transfer from intact erythrocytes during deoxygenation. Oxygenated, heparinized blood in a septated glass tonometer was treated with NAC $(100 \mu \mathrm{M})$ and deoxygenated with $95 \%$ argon $/ 5 \% \mathrm{CO}_{2}$. Serial samples underwent (a) co-oximetry; (b) plasma separation for SNOAC measurement by MS (see below); and (c) $\mathrm{SNO}_{\mathrm{rbc}}$ assay by chemiluminescence following reduction in a CuCl-saturated solution of $1 \mathrm{mM}$ cysteine purged with blended argon and CO, as previously described (11).

Primary cell cultures and other cell lines. Murine lungs were harvested in PBS containing heparin $(10 \mathrm{U} / \mathrm{ml}$ ) and $1 \%$ penicillin/streptomycin (Invitrogen; Millipore), minced, digested in $0.3 \%$ collagenase (PBS; $37^{\circ} \mathrm{C}$; $30-95$ minutes), and resuspended in DMEM with D-valine (Chemicon International; Millipore) containing 20\% FCS, $10 \mu \mathrm{M}$ HEPES, $2 \mathrm{mM}$ glutamine, $2 \mathrm{mM}$ sodium pyruvate, $1 \%$ nonessential amino acids, $90 \mu \mathrm{g} / \mathrm{ml}$ heparin, $100 \mu \mathrm{g} / \mathrm{ml}$ endothelial growth cell factor, $1 \%$ ITS reagent, $1 \%$ penicillin/streptomycin, $50 \mu \mathrm{M}$ 3-isobutyl-1-methylxanthine, $50 \mu \mathrm{M} N$-6-O-dibutyryl cAMP and $1 \mu \mathrm{g} / \mathrm{ml}$ hydrocortisone acetate. After 3 days' incubation $\left(37^{\circ} \mathrm{C}\right)$, cells were sorted for Dil- $\mathrm{A}_{\mathrm{c}}$-LDL uptake (Biomedical Technologies Inc.). Positive cells were cultured for 9-12 passages. BPAECs were isolated as previously described (5). COS cells were grown to confluence in DMEM/high glucose with 10\% FCS. 786-O cells (ATCC) and 780-O pVHL (gift from W. Kaelin, Dana Farber Cancer Institute, Harvard University, Boston, Massachusetts, USA) were grown in RPMI.

Immunoblotting. Immunoblot analysis on proteins isolated from lung homogenates, whole-cell extracts, and nuclear extracts was performed using antibodies against HIF1 $\alpha$ (Novus Biologicals), Sp3, neuronal NOS, VEGF-A, MAPK (Santa Cruz Biotechnology Inc.), HIMF (gift from Dechun Li, Saint Louis University, St. Louis, Missouri, USA), fibronectin (Abcam Inc.), eNOS, iNOS (BD Biosciences), and endothelin-1 (Research Diagnostics Inc.) as described previously $(5,14)$. 
Biotin substitution of S-nitrosothiol bonds. This was performed according to the method of Jaffrey et al. (49).

EMSA. EMSAs were performed on nuclear extracts using oligonucleotides and antibodies (for supershift) as described previously (5).

Real-time PCR. Messenger RNA was isolated from whole-lung homogenates by an RNA Easy kit (QIAGEN) as per the manufacturer's instructions. Expression of eNOS, VEGF, HIMF, fibronectin, and Glut-1 mRNA was assessed by real-time PCR using the primers (Integrated DNA Technologies Inc.) noted in Table 1 . The RT reaction was performed using $200 \mathrm{ng}$ RNA under the following conditions: $25^{\circ} \mathrm{C}$ for 10 minutes, $48^{\circ} \mathrm{C}$ 30 for minutes, and $95^{\circ} \mathrm{C}$ for 5 minutes using the Reverse Transcriptase Kit (Applied Biosystems), as described by the manufacturer, in the presence of SYBR Green Supermix (Bio-Rad). PCR cycles for HIMF were: $95^{\circ} \mathrm{C}$ for 3 minutes, $95^{\circ} \mathrm{C}$ for 30 seconds, $63^{\circ} \mathrm{C}, 72^{\circ} \mathrm{C}$ for 30 seconds; for VEGF: $95^{\circ} \mathrm{C}$ for 3 minutes, $95^{\circ} \mathrm{C}$ for 30 seconds, $60^{\circ} \mathrm{C}$ for 1 minute, $72^{\circ} \mathrm{C}$ for 1 minute; for eNOS: $95^{\circ} \mathrm{C}$ for 3 minutes, $95^{\circ} \mathrm{C}$ for 30 seconds, $58^{\circ} \mathrm{C}$ for 1 minute, $72^{\circ} \mathrm{C}$ for 1 minute; for fibronectin: $95^{\circ} \mathrm{C}$ for 3 minutes, $95^{\circ} \mathrm{C}$ for 30 seconds, $55.6^{\circ} \mathrm{C}$ for 1 minute, $72^{\circ} \mathrm{C}$ for 1 minute; for Glut-1: the same conditions as for VEGF, each for 50 cycles. Relative gene expression was determined according to Livak and Schmittgen (50).

Coimmunoprecipitation. COS cells were transiently transfected with HA-HIF-1 $\alpha$ and FLAG-pVHL using Lipofectamine 2000 (Invitrogen) according to the manufacturer's instructions. Following $S$-nitrosothiol treatment, cells were lysed in lysis buffer $(20 \mathrm{mM}$ Tris $\mathrm{pH} 7.6,150 \mathrm{mM} \mathrm{NaCl}, 10 \%$ glycerol, 2 mM EDTA $1 \%$ Triton X-100, $1 \mathrm{mM} \mathrm{Na}_{2} \mathrm{VO}_{4}, 1 \mu \mathrm{g} / \mathrm{ml}$ leupeptin, $1 \mathrm{mM}$ PMSF). Lysates were incubated with Flag M2 affinity gel (Sigma-Aldrich) ( 2 hours; $4^{\circ} \mathrm{C}$ ). The gel was washed 4 times in lysis buffer. Samples were eluted with $50 \mu \mathrm{l} 2 \times$ SDS buffer, heated $\left(100^{\circ} \mathrm{C} ; 3\right.$ minutes), and separated by $8 \%$ SDS-PAGE. HIF $1 \alpha$ was identified by immunoblot (5).

Nickel column isolation. BPAECs were transfected with HA-HIF- $1 \alpha$ and pCW-8, a His-6-Myc-tagged ubiquitin containing the K48R mutation (gift from R. Kopito, Stanford University, Palo Alto, California, USA), using Lipofectamine 2000. Untransfected and transfected cells were grown in the absence or presence of $S$-nitrosothiol $\left(21 \% \mathrm{O}_{2}\right)$ or in $10 \% \mathrm{O}_{2}$. Cells were lysed in the absence of EDTA, and lysates were passed over a ProBond Resin nickel column (Invitrogen) to isolate monoubiquitin-containing complexes. Complexes were eluted with imidazole and separated on $8 \%$ SDS-PAGE. HIF $1 \alpha$ protein was detected by immunoblot.
Site-directed mutagenesis of pVHL. pVHL was mutated using the QuickChange Site-Directed Mutagenesis Kit (Stratagene) according to the manufacturer's instructions using the following primers: $\mathrm{PVHL}$ C77S primer 1 , 5'-CCCTCCCAGGTCATCTTCTCTAATCGCAGTCCG-3'; primer 2, 5'CGGACTGCGATTAGAGAAGATGACCTGGGAGGG-3'; pVHL C162S primer 1, 5'-CTGAAAGAGCGATCGCTCCAGGTTGTCCGGAGC-3'; primer 2, 5'-GCTCCGGACAACCTGGAGCGATCGCTCTTTCAG-3'.

MS. Plasma $(100 \mu \mathrm{l})$ spiked with ${ }^{15} \mathrm{~N}$-labeled SNOAC was applied to a Phenomenex Strata XC $33 \mu \mathrm{M}$ SPE cartridge $(60 \mathrm{mg}, 3 \mathrm{ml})$, preequilibrated (and washed following loading) with methanol/0.02\% trifluoroacetic acid in water. Analytes were eluted with methanol and concentrated under reduced pressure $\left(0^{\circ} \mathrm{C}\right)$. Partially purified samples were reconstituted in methanol, separated on a C 8 column $(5 \mathrm{~mm}, 2.1 \times 150 \mathrm{~mm}$ ) (Waters 2695 HPLC) with a gradient of $0.1 \%$ formic acid in water and methanol, and analyzed by electrospray ionization MS using a Finnigan LCQ system. (Finnigan Corp.) SNOAC cations were monitored at a mass to charge ratio of 192.5-193.5.

Statistics. Multiple comparisons were made using ANOVA followed by pairwise analysis. Individual comparisons were made by Student's $t$ test if normally distributed; or otherwise by Mann-Whitney rank-sum test (using SigmaStat; Jandel). Relative gene expression by RT-PCR was quantitated as above (50). Except where noted, data are presented as mean \pm SD. $P<0.05$ was considered significant.

\section{Acknowledgments}

We thank Dechun Li for the gift of HIMF antibody; Kimberly DeRonde, Kathleen Brown-Steinke, Jaclyn Kline, Edward Henderson, and Joseph Doherty for technical assistance; and Brian Duling for his thoughtful comments on the manuscript. This work was supported by NIH grants HL068173 (to L.A. Palmer), HL059337 (to B. Gaston), and 1KO8GM069977 (to A. Doctor).

Received for publication June 20, 2006, and accepted in revised form May 24, 2007.

Address correspondence to: Benjamin Gaston, Pediatric Respiratory Medicine University of Virginia Health System, Box 800386, Charlottesville, Virginia 22908, USA. Phone: (434) 924-1820; Fax: (434) 924-8388; E-mail: bmg3g@virginia.edu.
1. Gaston, B., Doctor, A., Singel, D., and Stamler, J.S. 2006. S-Nitrosothiol signaling in respiratory biology. Am. J. Respir. Crit. Care Med. 173:1186-1193.

2. Kim, S.F., Huri, D.A., and Snyder, S.H. 2005. Inducible nitric oxide synthase binds, S-nitrosylates and activates cyclooxygenase-2. Science. 310:1966.

3. Lipton, A.J., et al. 2001. S-Nitrosothiols signal the ventilatory response to hypoxia. Nature. 413:171-174.

4. Jia, L., Bonaventura, C., Bonaventura, J., and Stamler, J.S. 1996. S-Nitrosohaemoglobin: a dynamic activity of blood involved in vascular control. Nature. 380:221-226.

5. Palmer, L.A., Gaston, B., and Johns, R.A. 2000. Normoxic stabilization of hypoxia-inducible factor- 1 expression and activity: redox-dependent effect of nitrogen oxides. Mol. Pharmacol. 58:1197-1203.

6. Liu, L., et al. 2004. Essential roles of S-nitrosothiols in vascular homeostasis and endotoxic shock. Cell. 116:617-628.

7. Farber, H.W., and Loscalzo, J. 2004. Pulmonary arterial hypertension. N. Engl. J. Med. 351:1655-1665

8. Blaise, G., Langleben, D., and Hubert, B. 2003. Pulmonary arterial hypertension: pathophysiology and anesthetic approach. Anesthesiology. 99:1415-1432.

9. Semenza, G.L. 2004. $\mathrm{O}_{2}$-regulated gene expression: transcriptional control of cardiorespiratory physiology by HIF-1. J. Appl. Physiol. 96:1173-1177.
10. Jiang, B.H., Semenza, G.L., Bauer, C., and Marti, H. 1996. Hypoxia-inducible factor 1 levels vary exponentially over a physiologically relevant range of $\mathrm{O}_{2}$ tension. Am. J. Physiol. 271:C1172-C1180.

11. Doctor, A., et al. 2005. Hemoglobin conformation couples erythrocyte $\mathrm{S}$-nitrosothiol content to $\mathrm{O}_{2}$ gradients. Proc. Natl. Acad. Sci. U. S. A. 102:5709-5714.

12. Pawloski, J.R., Hess, D.T., and Stamler, J.S. 2001. Export by red blood cells of nitric oxide bioactivity. Nature. 409:622-626.

13. Sandau, K.B., Faus, H.G., and Brune, B. 2000. Induction of hypoxia-inducible-factor 1 by nitric oxide is mediated via the PI $3 \mathrm{~K}$ pathway. Biochem. Biophys. Res. Com. 278:263-267.

14. Zaman, K., Palmer, L.A., Doctor, A., Hunt, J.F., and Gaston, B. 2004. Concentration-dependent effects of endogenous S-nitrosoglutathione on gene regulation by specificity proteins $\mathrm{Sp} 3$ and $\mathrm{Sp} 1$. Biochem. J. 380:67-74.

15. Ricardo, K., Shishido, S., de Oliveira, M., and Krieger, M. 2002. Characterization of the hypotensive effect of S-nitroso-N-acetylcysteine in normotensive and hypertensive conscious rats. Nitric Oxide. 7:57-66.

16. Teng, X., Li, D., Champion, H.C., and Johns, R.A. 2003. FIZZ1/RELMalpha, a novel hypoxia-induced mitogenic factor in lung with vasoconstrictive and angiogenic properties. Circ. Res. 92:1065-1067.
17. Vyas-Somani, A.C., et al. 1996. Temporal alterations in basement membrane components in the pulmonary vasculature of the chronically hypoxic rat: impact of hypoxia and recovery. Am. J. Med. Sci. 312:54-67.

18. Le Cras, T.D., et al. 1999. Effects of chronic hypoxia and altered hemodynamics on endothelial nitric oxide synthase expression in the adult rat lung. J. Clin. Invest. 101:795-801.

19. Lam, C.-F., Peterson, T.E., Croatt, A.J., Nath, K.A., and Katusic, Z.S. 2005. Functional adaptation and remodeling of pulmonary artery in flow-induced pulmonary hypertension. Am. J. Physiol. Heart Circ. Physiol. 289:H2334-H2341.

20. Xue, C., and Johns, R.A. 1996. Upregulation of nitric oxide synthase correlates temporally with onset of pulmonary vascular remodeling in the hypoxic rat. Hypertension. 28:743-753.

21. Tyler, R.C., et al. 1999. Variable expression of endothelial NO synthase in three forms of rat pulmonary hypertension. Am. J. Physiol. 276:L297-L303.

22. Kanazawa, F., et al. 2005. Expression of endothelin-1 in the brain and lung of rats exposed to permanent hypobaric hypoxia. Brain Res. 1036:145-154.

23. Grover, T.R., et al. 2003. Intrauterine hypertension decreases lung VEGF expression and VEGF inhibition causes pulmonary hypertension in the 
ovine fetus. Am. J. Physiol. Lung Cell Mol. Physiol. 284:L508-L517.

24. Zhao, Y.D., et al. 2006. Microvascular regeneration in established pulmonary hypertension by angiogenic gene transfer. Am. J. Respir. Cell Mol. Biol. 35:182-189.

25. Li, Q., and Dai, A. 2004. Hypoxia-inducible factor1 alpha regulates the role of vascular endothelial growth factor on pulmonary arteries of rats with hypoxia-induced pulmonary hypertension. Chin. Med. J. 117:1023-1028.

26. Hoehn, T., et al. 2003. Endothelial nitric oxide synthase (NOS) is upregulated in rapid progressive pulmonary hypertension of the newborn. Intensive Care Med. 29:1757-1762.

27. Shesely, E.G., et al. 1996. Elevated blood pressures in mice lacking endothelial nitric oxide synthase. Proc. Natl. Acad. Sci. U. S. A. 93:13176-13181.

28. Steudel, W., et al. 1998. Sustained pulmonary hypertension and right ventricular hypertrophy after chronic hypoxia in mice with congenital deficiency of nitric oxide synthase 3. J. Clin. Invest. 101:2468-2477.

29. Fagan, K.A., et al. 1999. The pulmonary circulation of homozygous or heterozygous eNOS-null mice is hyperresponsive to mild hypoxia. J. Clin. Invest. 103:291-299.

30. Hunninghake, G.W. 2005. Antioxidant therapy for idiopathic pulmonary fibrosis. N. Engl. J. Med. 353:2285-2287.

31. Springer, J., and Fischer, A. 2003. Substance Pinduced pulmonary vascular remodelling in precision cut lung slices. Eur. Respir. J. 22:596-601.

32. Shatrov, V.A., Sumbayev, V.V., Zhou, J., and Brüne, B. 2003. Oxidized low-density lipoprotein (oxLDL) triggers hypoxia-inducible factor $1 \alpha(\mathrm{HIF}-1 \alpha)$ accumulation via redox-dependent mechanisms. Blood. 101:4847-4849.

33. Scharfstein, J.S., et al. 1994. In vivo transfer of nitric oxide between a plasma protein-bound reservoir and low molecular weight thiols. J. Clin. Invest.
94:1432-1439.

34. McMahon, T.J., et al. 2005. A nitric oxide processing defect of red blood cells created by hypoxia: deficiency of S-nitrosohemoglobin in pulmonary hypertension. Proc. Natl. Acad. Sci. U. S. A. 102:14801-14806.

35. Gaston, B., et al. 1993. Endogenous nitrogen oxides and bronchodilator S-nitrosothiols in human airways. Proc. Natl. Acad. Sci. U. S. A. 90:10957-10961.

36. Wada, T., Shimba, S., and Tezuka, M. 2006. Transcriptional regulation of the hypoxia inducible factor 2alpha (HIF-2alpha) gene during adipose differentiation in 3T3-L1 cells. Biol. Pharm. Bull. 29:49-54.

37. Sumbayev, V.V., Budde, A., Zhou, J., and Brüne, B. 2003. HIF-1 alpha protein as a target for S-nitrosation. 2003. FEBS Lett. 535:106-112.

38. Zhou, J., and Brüne, B. 2005. NO and transcriptional regulation: from signaling to death. Toxicology. 208:223-233.

39. Metzen, E., Zhou, J., Jelkmann, W., Fandrey, J., and Brüne, B. 2003. Nitric oxide impairs normoxic degradation of HIF- $1 \alpha$ by inhibition of prolyl hydroxylases. Mol. Biol. Cell. 14:3470-3481.

40. Kohl, R., Zhou, J., and Brüne, B. 2006. Reactive oxygen species attenuate nitric-oxide-mediated hypoxia-inducible factor-1alpha stabilization. Free Radic. Biol. Med. 40:1430-1442.

41. Jeffers, A., et al. 2005. Hemoglobin mediated nitrite activation of soluble guanylyl cyclase. Comp. Biochem. Physiol. A Mol. Integr. Physiol. 142:130-135.

42. Masson, N., Willam, C., Maxwell, P.H., Pugh, C.W., and Ratcliffe, P.J. 2001. Independent function of two destruction domains in hypoxia-inducible factor-alpha chains activated by prolyl hydroxylation. EMBO J. 20:5197-5206.

43. Ivan, M., et al. 2001. HIF $\alpha$ targeted for VHL-mediated destruction by proline hydroxylation: implications for $\mathrm{O}_{2}$ sensing. Science. 292:464-468.

44. Yao, D., et al. 2004. Nitrosative stress linked to sporadic Parkinson's disease: S-nitrosylation of Parkin regulates its E3 ligase activity. Proc. Natl. Acad. Sci. U. S. A. 101:10810-10814.

45. Lonergan, K.M., et al. 1998. Regulation of hypoxiainducible mRNAs by the von Hippel-Lindau tumor suppressor protein requires binding to complexes containing elongins B/C and Cul2. Mol. Cell. Biol. 18:732-741.

46. Ohh, M., et al. 2000. Ubiquitination of hypoxiainducible factor requires direct binding to the betadomain of the von Hippel-Lindau protein. Nat. Cell Biol. 2:423-427.

47. Stebbins, C.E., Kaelin, W.G., Jr., and Pavletich, N.P. 1999. Structure of the VHL-ElonginC-ElonginB complex: implications for VHL tumor suppressor function. Science. 284:455-461.

48. Hildebrandt, W., Alexander, S., Bartsch, P., and Droge, W. 2002. Effect of N-acetyl-cysteine on the hypoxic ventilatory response and erythropoietin production: linkage between plasma thiol redox state and $\mathrm{O}(2)$ chemosensitivity. Blood. 99:1552-1555.

49. Jaffrey, S.R., Erdjument-Bromage, H., Ferris, C.D., Tempst, P., and Snyder, S.H. 2001. Protein S-nitrosylation: a physiological signal for neuronal nitric oxide. Nat. Cell Biol. 3:193-197.

50. Livak, K.J., and Schmittgen, T.D. 2001. Analysis of relative gene expression data using real-time quantitative PCR and the $2^{-\Delta \Delta C}$ Tethod. Methods. 25:402-408.

51. Loke, P., Nair, M.G., Parkinson, J., Guiliano, D., and Allen, M.E. 2002. IL4-dependent alternativelyactivated macrophages have distinctive in vivo gene expression phenotype. BMC Immunol. 3:7.

52. Chintalgattu, V., Nair, D.M., and Katwa, L.C. 2003. Cardiac myofibroblasts: a novel source of vascular endothelial growth factor (VEGF) and its receptors Ft-1 and KDR. J. Mol. Cell. Cardiol. 35:277-286.

53. Tang, Y., et al. 2006. Effect of hypoxic preconditioning on brain genomic response before and following ischemia in the adult mouse: identification of potential neuroprotective candidates for stroke. Neurobiol. Dis. 21:18-28. 